\title{
Emerging Trends in the use of IoT in Agriculture and Food Supply Chain Management: A Theoretical Analysis
}

\author{
Dr. Sajoy P.B \\ Assistant Professor, Post Graduate Research Department of Commerce, Sacred Heart College (Autonomous), Thevara, \\ Cochin, India \\ sajoypb@shcollege.ac.in
}

Article History: Received: 10 November 2020; Revised 12 January 2021 Accepted: 27 January 2021; Published online: 5 April 2021

\begin{abstract}
The last decade has seen the Internet of Things (IoT) taking the world by storm. IoT has the ability to provide a wide range of services in real-time without any form of human intervention. Its most recent application is in the field of agriculture and food supply chain management. The use of IoT in agriculture and food supply chain management is expected to boost agriculture production as well as improve the quality of food products supplied to customers among other things. The use of IoT in agriculture and food supply chain management has however, raises several issues and concerns including those relating to privacy.
\end{abstract}

Keywords: Internet of Things (IoT); Agriculture and Food Supply Chain (AFSC); Big Data; Things Related Services

\section{Introduction}

The world population is growing at an average annual rate of about 1.1 percent [1]. The world population is expected to touch 10 billion by the middle of this century [2]. To feed such a large population, the world food production has to be increased by at least $70 \%$ by 2050 [3]. This is a great challenge considering the fact that the availability of land suitable for agriculture is gradually reducing due to the increasing pressure on land as a result of population growth [4]. Thus, the ever-increasing need for food products can be met only by adopting innovative methods.

The last fifty years has seen the emergence of Internet and Information and Communication Technology (ICT). But, hitherto, these technologies did not have any significant direct impact on agriculture/food production. However, the emergence of Internet of Things (IoT) is changing the game. In IoT technology, a large number of objects or things which are capable of monitoring their environment, reporting their own status, receiving information/instructions and taking action based on the information/instructions so received, without any human intervention, are inter-connected together via the Internet [5]. IoT is capable of converting raw physical data like temperature, humidity, pressure, speed, flow, etc. into an identifiable virtual or electronic representation without any human intervention [6]. This unique feature of IoT is now being made use in agriculture and food supply chain management not only to improve agricultural production but also to make efficient use of the agricultural produce by minimizing loss. This article seeks to briefly look at the recent trends in the use of IoT in Agriculture and Food Supply Chain Management (AFSCM).

\section{Defining IoT}

Internet of Things (IoT) are internet-based networks that connects objects/things together for the purpose of extracting information from the environment (sensing) and interacting with the physical world (actuation/command/control). It also uses the existing Internet for the purpose of transmitting the information so collected from one location to another [7]. The physical objects/things, which are part of IoT, are fitted with sensors. Those sensors are able to measure/monitor various environmental variables like temperature, soil PH, humidity, etc. and convert them into electronic data capable of transmitted, stored and analyzed in the virtual world [8]. All these processes happen in real-time without any form of human intervention [9].

The following are some of the key features of IoT [8], [10]:

i. $\quad$ Sensing capacity: - IoT devices (things/objects) are fitted with sensors, which are capable of measuring different variables like temperature, soil PH, humidity, pressure etc. [11].

ii. Heterogeneity: - The architecture of IoT is flexible enough to support different types of underlying networks, different types of communication devices and different addressing modes [12]. 
iii. Ability to function without human intervention: - IoT has the ability to self-configure, self-organise, selfadapt to dynamic situations and self-process huge amounts of data without any form of human intervention, in real-time [8].

iv. Reliability and secure environment: - The design of IoT networks and devices are such that it is possible to incorporate a very high degree of reliability and security into the IoT system [8], [11], [13].

v. Things related services: - The key feature of IoT is that it is capable of providing thing-related services. This is an improvement from the existing ICT technologies which provided people related services [14]. IoT is capable of providing thing related services within certain limitations like privacy, sematic consistency between physical things and their associated virtual representation etc. [11].

vi. Dynamic and enormous scale of the IoT network: - The number of devices connected to IoT is of a gigantic proportion. It is predicted that by the end of last year (2020) about 25 million devices would have been connected to the Internet via IoT [9]. Further, the state of the IoT devices is subject to constant dynamic changes [11].

vii. Big data generation and processing: - Since billions of IoT devices are connected together in the IoT network, massive amounts of data is generated every second which is transmitted, processed and stored securely [15].

\section{Architecture of IoT}

In its basic technical form, the IoT has a three-layer vertical architecture. These three layers are the sensing layer, the network layer and the application layer [16]. The said architecture scheme is represented in the figure - 1 below [17].

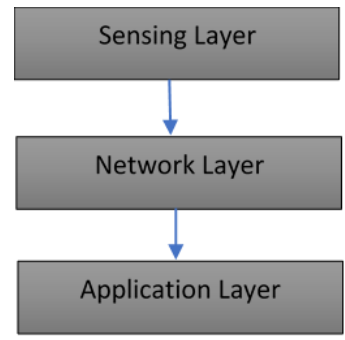

Figure 1: Architectural representation of IoT

Source: [17]

i. $\quad$ Sensing layer: - It is an also called as the perception layer [18]. It is the physical layer which has sensors for sensing and gathering information about the environment [19]. The sensors enable the interconnection of the physical and digital worlds by permitting the collection/processing of real-time information. The sensors have the capacity to measure various parameters like temperature, air quality, soil PH, speed, humidity, pressure, flow, movement electricity etc. [11].

ii. Network layer: - It is also known as the transmission layer [18] or communication layer [17]. The basic function of the network layer is to transmit the data collected by the sensing layer to the application layer [16]. The network layer is also responsible for inter-connecting the different IoT devices together [19]. Physically, the network layer consists of inter-connected heterogenous network systems like satellite communication systems, Bluetooth, wireless communication, mobile communication, global positioning system (GPS) etc. [16].

iii. Application layer: - Providing specific services to users is the primary task of the application layer [19]. It is the application layer that determines the various applications in which IoT can be used. The type of service provided by the application layer depends upon the type of data collected by the sensor layer [18]. Thus, the application layer acts as the interface between the user and the system [20].

\section{Agriculture and Food Supply Chain and its Management}

Agriculture and Food Supply Chain (AFSC) refers to a set of processes through which food grown in the farm has to move, before it reaches the final customer. It involves the whole product flow from growing seedlings to the delivery of the final product to the customers [21]. It includes within its fold (i) suppliers of agricultural inputs like seeds, fertilizers, pesticides and other agricultural production materials. (ii) Producers of agricultural products (farmers), (iii) agricultural product processing enterprises, (iv) distributors (both wholesale and retail) and (v) consumers of agricultural products [22]. The agricultural and food supply chain can be pictorially represented in figure - 2 below.

The proper management of agricultural and food supply chain is of utmost importance for the economy of any country including India. The need is not just to boost agriculture production but also to protect the agricultural produce till it is consumed. It is estimated that $30 \%$ of all food products are lost between production and 
consumption due to improper management [23]. This calls for proper management of the agriculture and food supply chain. Efficient management of the agriculture and food supply chain is also essential for ensuring food quality across the supply chain [24].

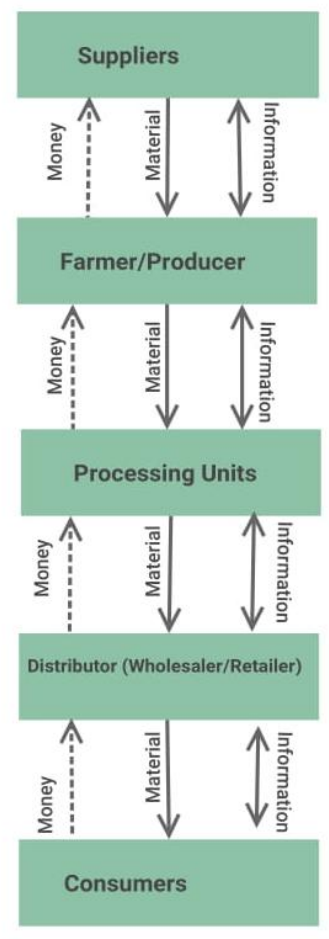

Figure 2: Agricultural and Food Supply Chain

(Source: Adapted from [25])

\section{Implementation of IoT in Agriculture and Food Supply Chain Management}

One of the major application areas for IoT is in the field of agriculture and food supply chain management. IoT is capable of offering solutions to the various problems and challenges faced by the actors in the agriculture and food supply chain like shortage of water, shortage of inputs, cost management, productivity issues, etc. [26]. IoT can be implemented in all the different stages of the agricultural and food supply chain. Hence, there are numerous applications of IoT in field of Agriculture and Food Supply Chain Management. These include (i) Application of IoT at the farming/production stage (ii) application of IoT at the distribution/transport stage and storage stage (iii) Application of IoT at consumption stage and (iv) application of IoT at the waste/disposal stage [27].

i. $\quad$ Application of IoT at the farming/production stage: - The application of IoT at the farming /production stage helps improve crop yield and also reduces the usage of fertilizers, water, pesticides, etc. Farmers are able to get real-time information about crop health, weather conditions, soil quality, etc. without actually going to the farm. This data helps farmer predict the crop yield more accurately. Use of IoT also enables farmers to reduce dependence on human labour for agricultural activities [23].

ii. Application of IoT at the distribution/transport stage and storage stage: - Most food items are products with short shell life. Hence there is a need to constantly monitor the freshness of the food items, particularly perishables, at every stage of transport, distribution and storage [28]. IoT devices fitted with sensors are used to monitor and control temperature, humidity and related environmental factors during all stages of transport, distribution and storage. IoT devices are also used to track the location of food items during transit from one place to another [23].

iii. Application of IoT at the consumption stage: - There are numerous applications of IoT at the consumption stage. For example, IoT enabled digital weighing machines can be used to weigh agricultural products supplied to customers. Since the calibration of the digital weighing machines can be regularly monitored using IoT technology, it is difficult to tamper with the calibration of those weighing machines [29].

iv. Application of IoT at the stage of waste/disposal: - IoT is also being extensively used to solve the problems of agriculture/food waste. For this purpose, various types of smart garbage systems are being developed [30]. 


\section{Issues and Concerns}

IoT is being increasingly used for managing the agriculture and food supply chain. This is due to the obvious advantages offered by IoT. However, the use of IoT in agriculture are not without issues and concerns. Some of them are outlined below:

i. IoT devices used in agriculture and food supply chain function under harsh environmental conditions like high temperature, humidity, rain, etc. Hence there is a possibility of IoT devices malfunctioning leading to wrong measurement [31].

ii. The farmers and other actors in the agriculture and food supply chain are not trained and hence they are not equipped to deal with IoT devices and its technology. Consequently, they may not be able to fully reap the benefits of the use of IoT in the management of agriculture and food supply chain [32].

iii. IoT devices capture a lot of data. This data has to be adequately protected. For this purpose, numerous security measures have to be adopted, leading to increased costs [33].

iv. Full benefits of use of IoT in the management of agriculture and food supply chain management can be derived only if all farmers/producers in an area adopt IoT technology. However, it is possible that some farmers may opt out [32].

v. For the purpose of transmitting the raw data collected by IoT devices to the nearest data centre, IoT devices most often make use of wireless networks [34] Making available reliable wireless network round the clock in rural areas is a daunting task.

vi. Most farmers, particularly farmers in India are poor marginal farmers. They are not in a financial portion to meet the cost of implementing IoT [32].

vii. The IoT network is vulnerable to cyber-attack from cyber criminals. In order to protect the IoT network from such attacks, it becomes necessary to adopt costly cyber security measures [31].

\section{conclusion}

Even though, Internet of Things, became popular more than a decade ago, its full-scale use in agriculture and food supply chain is more recent. Farmers and other actors in the agriculture and food supply chain are to greatly benefit, if IoT is fully implemented in the management of the agriculture and food supply chain. In a country like India, massive large-scale implementation of IoT in agriculture and food supply chain is very difficult due to the marginal nature of most agricultural holdings coupled with extreme poverty. Hence, IoT can be implemented in India on a large scale, only if the central and state governments make substantial investments.

\section{References}

United Nations, "World Population Prospects 2019: Highlights (ST/ESA/SER.A/423)," New York, 2019. [Online]. Available: http://www.ncbi.nlm.nih.gov/pubmed/12283219.

J. Cleland, "World Population Growth; Past, Present and Future," Environ. Resour. Econ., vol. 55, no. 4, pp. 543-554, 2013, doi: 10.1007/s10640-013-9675-6.

FAO, "Global Agriculture towards 2050," How to Feed the World 2050 - High Level Expert Forum. United Nations, Rome, p. 4, 2018.

N. Birdsall, A. C. Kelley, S. Sinding, and J. Pender, "Rural Population Growth, Agricultural Change, and Natural Resource Management in Developing Countries: A Review of Hypotheses and Some Evidence from Honduras," Popul. Matters, no. 48, pp. 325-368, 2003, doi: 10.1093/0199244073.003.0012.

R. Minerva, A. Biru, and D. Rotondi, Towards a definition of the Internet of Things (IoT), no. 1. IEEE Internet Initiative, 2015.

P. B. Sajoy, "Reinventing Supply Chain Management using Internet of Things," in Multidisciplinary Subjects for Research, R. B. . Saksena and D. A. Ode, Eds. Stockholm,Sweden: Redshine Publication, 2020, pp. 148-152.

J. Gubbi, R. Buyya, S. Marusic, and M. Palaniswami, "Internet of Things (IoT): A vision, architectural elements, and future directions," Futur. Gener. Comput. Syst., vol. 29, no. 7, pp. 1645-1660, Sep. 2013, doi: 10.1016/j.future.2013.01.010.

N. C. Luong, D. T. Hoang, P. Wang, D. Niyato, D. I. Kim, and Z. Han, "Data Collection and Wireless Communication in Internet of Things (IoT) Using Economic Analysis and Pricing Models: A Survey," IEEE Commun. Surv. Tutorials, vol. 18, no. 4, pp. 2546-2590, 2016, doi: 10.1109/COMST.2016.2582841.

A. S. Abdul-Qawy, P. P.J, E. Magesh, and T. Srinivasulu, "The Internet of Things: An Overview," J. Eng. Res. Appl., vol. 5, no. 12, pp. 71-82, 2015.

E. Borgia, "The internet of things vision: Key features, applications and open issues," Comput. Commun., vol. 54, pp. 1-31, 2014, doi: 10.1016/j.comcom.2014.09.008.

K. K. Patel, S. M. Patel, and P. G. Scholar, "Internet of Things-IOT: Definition, Characteristics, Architecture, Enabling Technologies, Application \&amp; Future Challenges,” Int. J. Eng. Sci. Comput., vol. 6, no. 5, pp. 1-10, 2016, doi: 10.4010/2016.1482. 
V. Aleksandrovičs, E. Filičevs, and J. Kampars, "Internet of Things: Structure, Features and Management," Inf. Technol. Manag. Sci., vol. 19, no. 1, pp. 78-84, 2017, doi: 10.1515/itms-2016-0015.

S. Pokorni, "Reliability and availability of the Internet of things," Vojnoteh. Glas., vol. 67, no. 3, pp. 588-600, 2019, doi: 10.5937/vojtehg67-21363.

M. Gigli and S. Koo, "Internet of Things: Services and Applications Categorization," Adv. Internet Things, vol. 01, no. 02, pp. 27-31, 2011, doi: 10.4236/ait.2011.12004.

S. Khare and M. Totaro, "Big Data in IoT," 2019 10th Int. Conf. Comput. Commun. Netw. Technol. ICCCNT 2019, no. July 2019, 2019, doi: 10.1109/ICCCNT45670.2019.8944495.

G. Witjaksono, A. A. Saeed Rabih, N. B. Yahya, and S. Alva, "IOT for Agriculture: Food Quality and Safety," IOP Conf. Ser. Mater. Sci. Eng., vol. 343, no. 1, 2018, doi: 10.1088/1757-899X/343/1/012023.

S. Nirenjena, D. L. BalaSubramanian, and M. Monisha, "Advancement in monitoring the food supply chain management using IOT,” Int. J. Pure Appl. Math., vol. 119, no. 14, pp. 1193-1196, 2018.

M. K. Özlen and F. Hasanspahic, "Top rated supply chain related factors in a specific journal: a keyword analysis," Glob. Bus. Econ. Res. J., vol. 2, no. 6, pp. 26-37, 2013, [Online]. Available: http://journal.globejournal.org/index.php/GBERJ/article/view/49.

P. Sethi and S. R. Sarangi, "Internet of Things: Architectures, Protocols, and Applications," J. Electr. Comput. Eng., vol. 2017, 2017, doi: 10.1155/2017/9324035.

V. S. Venkateshwar and M. Mohiddin, "A Survey on Smart Agriculture using IOT,” in ICPCN, 2017, vol. 5, no. 19, pp. 1-6.

Y. Duan, "Research on Integrated Information Platform of Agricultural Supply Chain Management Based on Internet of Things," J. Softw., vol. 6, no. 5, pp. 944-950, May 2011, doi: 10.4304/jsw.6.5.944-950.

L. Zhang, "Application of IOT in the Supply Chain of the Fresh Agricultural Products," no. Cimns, pp. 201-204, 2016, doi: 10.2991/cimns-16.2016.50.

S. Vermani, "Farm to fork: IOT for food supply chain,” Int. J. Innov. Technol. Explor. Eng., vol. 8, no. 12, pp. 4915-4919, 2019, doi: 10.35940/ijitee.L3551.1081219.

X. Zhao, H. Fan, H. Zhu, Z. Fu, and H. Fu, "The Design of the Internet of Things Solution for Food Supply Chain," no. Emim, pp. 314-318, 2015, doi: 10.2991/emim-15.2015.61.

G. Gebresenbet and T. Boso, "Logistics and Supply Chains in Agriculture and Food," in Pathways to Supply Chain Excellence, no. March 2012, InTech, 2012, pp. 125-146.

M. S. Farooq, S. Riaz, A. Abid, K. Abid, and M. A. Naeem, "A Survey on the Role of IoT in Agriculture for the Implementation of Smart Farming," IEEE Access, vol. 7, pp. 156237-156271, 2019, doi: 10.1109/ACCESS.2019.2949703.

R. Accorsi, M. Bortolini, G. Baruffaldi, F. Pilati, and E. Ferrari, "Internet-of-things Paradigm in Food Supply Chains Control and Management," Procedia Manuf., vol. 11, no. September 2018, pp. 889-895, 2017, doi: 10.1016/j.promfg.2017.07.192.

P. Wadhwa, "Fresh Food Supply Chain Management using IoT," vol. 3, no. 1, pp. 127-130, 2018.

D. Chakraborty, "IoT \& Agricultural Marketing: A Case Study," vol. 9, no. 1, pp. 50-54, 2018.

I. Hong, S. Park, B. Lee, J. Lee, D. Jeong, and S. Park, "IoT-Based Smart Garbage System for Efficient Food Waste Management," Sci. World J., vol. 2014, 2014, doi: 10.1155/2014/646953.

A. Grogan, "Smart farming," Eng. Technol., vol. 7, no. 6, pp. 38-40, 2012, doi: 10.1049/et.2012.0601.

M. Ayaz, M. Ammad-Uddin, Z. Sharif, A. Mansour, and E. H. M. Aggoune, "Internet-of-Things (IoT)-based smart agriculture: Toward making the fields talk," IEEE Access, vol. 7, pp. 129551-129583, 2019, doi: 10.1109/ACCESS.2019.2932609.

I. Affia, L. P. E. Yani, and A. M. Aamer, "Factors affecting IoT adoption in food supply chain management," in 9th International Conference on Operations and Supply Chain Management, 2019, no. December, pp. 19-24.

S. Anwar, "Internet of Things (IoT) in Healthcare - An Introduction," Rai Jounal Technol. Res. Innov., vol. V, no. I, pp. 28-31, 2017 